\title{
Quality of Service to Users of Primary Health Care: A Study of Evaluation
}

\author{
Fábia Barbosa de Andrade ${ }^{1}$, Iris do Ceu Clara Costa ${ }^{2}$, Tainara Lôrena dos Santos Ferreira1, \\ Dayane Caroliny Pereira Justino', Luanni Rayssa de Medeiros Souza1, \\ Cláudia Janiele Batista Fonsêca1, Paula Thayse Costa Fernandes', \\ Andréia Geíse Gomes de Araújo ${ }^{1}$ \\ ${ }^{1}$ Faculty of Health Sciences of Trairi (FACISA), Federal University of Rio Grande do Norte (UFRN), \\ Santa Cruz, Brazil \\ ${ }^{2}$ Department of Dentistry, Federal University of Rio Grande do Norte (UFRN), Natal, Brazil \\ Email: fabiabarbosabr@yahoo.com.br, iris odontoufrn@yahoo.com.br, tainara_lorena@hotmail.com, \\ daycaroliny@hotmail.com, luannid@hotmail.com, claudiajaniele@hotmail.com, \\ thayse fernandes12@hotmail.com, andreiageise@hotmail.com
}

Received 31 December 2014; accepted 6 February 2015; published 13 February 2015

Copyright @ 2015 by authors and Scientific Research Publishing Inc.

This work is licensed under the Creative Commons Attribution International License (CC BY).

http://creativecommons.org/licenses/by/4.0/

(c) (i) Open Access

\begin{abstract}
The quality of service to people in Primary Healthcare (PHC) is linked to the provision of quality service by professionals who integrate this service in the community. Accordingly, this study aims to evaluate the service given by health professionals in primary health care, from the user's perception. This is an evaluative and quantitative study, conducted with people who use the PHC service. 180 adults are interviewed in the city of Santa Cruz, Rio Grande do Norte, Brazil. The results show that most respondents are women. The average age is of 36.65, median of 34.00 and standard deviation of 11,554. With regards to the quality of service, it ranges from fair to good. When performing correlation between the quality of service and time spent to reach the service, most people say that they spend between 0 and 15 minutes from their house to the healthcare service unit. About reception, respondents reported being satisfied and that the service has been responsible and quality for health monitoring. Thus, it is noted that the user classifies the quality of the service in primary healthcare as regular, showing weaknesses that need to be corrected to prevent damage in service provision in Primary Healthcare.
\end{abstract}

\section{Keywords}

Primary Healthcare, Adult's Health, Public Health, Nursing 


\section{Introduction}

The Primary Healthcare (PHC) has been suggested in Brazil as the level of service that is the closest to the area where the family resides. In this territory are present all geographical, economic, regional and social characteristics, and along with them, the health-disease process. Therefore, it is necessary to accept the human being in its needs in this level of service, in order to strengthen the construction of connections.

The reception is directly connected to the humanization, which has to be paramount to the existence of a good relationship between users and healthcare professionals, since it better promotes access to healthcare for the population. Thus, it should go much further, given that it is necessary for professionals to listen to the population's health problems, the service must happen in a qualified manner, there must always be a positive answer to the problem that the user has and above all, there must be responsibility and commitment to provide a resolution to the same [1].

Besides the way the service occurs, it is important that the healthcare professionals have the actual knowledge of the population of their location of work, because when one knows the patient's reality, there is a greater possibility of solving health problems. To Pereira et al. [1] when one recognizes the patient's needs, healthcare professionals have to work in the care of the human being, emphasizing their uniqueness, their knowledge, their needs and the reality experienced by him/her.

Achieving quality in products and services has become a general concern since 1980, especially in the healthcare sector, where service quality is difficult to measure and is often mistaken with productivity. It is important to emphasize that the quality of health services is related to specific dimensions, such as structure, process and outcome. Patient satisfaction can be defined as a personal assessment about health services that may not be evaluated through direct observation. The opinion of the patient can be considered a subjective and multidimensional indicator of the quality of the health service [2].

Thus, it is up to the professional working in the PHC to accommodate the patient in a humane way and listen to him/her when needed. Because, as it is known, users often seek health services just to be heard. This professional must be qualified and attentive to point a solution to the complaints heard.

People can express their understanding of their health problem in different ways. Therefore, a better care from the professional's during an appointment is necessary, for the purpose of understanding and paying attention when listening to the patients. Professionals are not exempt from making diagnosis mistakes, neither in the guidelines that must be passed on to patients, and that can also be understood in a wrong manner by them [3].

Concerning the understanding about the information given to patients by health professionals, there are meanings of scientific terms that users are unaware of, not to mention that there may be a lack of dialogue between the professional and the patient. According to Oenning, Oliveira and Blatt [4], there is a low level of knowledge of users in relation to medicament administration, a fact that highlights the idea that many use the remedies without knowing at least their usefulness, their proper management and/or for how long one must keep on taking the medicine.

In this sense, it is necessary to clarify the orientations given to patients; professional training is also needed, as well as a greater involvement when these orientations are given. Thus the appointment should be used to answer any questions that the patient may have regarding his/her condition and/or treatment [4].

Thus, it will be important to ascertain the forms of service performed in primary health care, to verify the reception, the humanization and attention given to users in this health network; so that, if necessary, take measures to improve the service, causing the users to seek this service increasingly.

In PHC, it is important and collaborative to know the user's perception about the quality of services and consultations offered by health professionals and received by them. Because, from the moment the results are acquired, one may intervene in the strategic health planning and develop optimized goals. Thus, this study is justified by its contribution to improve the service to the primary care user, because his/her goal is to evaluate the service given by health professionals in primary health care, from the user perception.

\section{Methodology}

This is an evaluative quantitative study, of descriptive character, with data collection performed through interviews with elderly people who use the PHC services in the city of Santa Cruz, in the State of Rio Grande do Norte, Brazil.

This study is a part of a research entitled: Primary Attention to Health: an evaluation study from the users' 
perspective. The sample was consisted of 180 adults aged between 20 and 59 years, using the instrument Primary Care Assessment Tool (the PCA Tool), a questionnaire based on the following guiding pillars of primary health care: first contact access, comprehensiveness, longitudinality, coordination, family and community orientation and cultural competence.

The study was approved by the Research Ethics Committee (REC) of the Federal University of Rio Grande do Norte (UFRN), under Opinion number 152/2012, and followed the recommendations for research with human beings. All study participants signed a consent form prior to data collection because they are compatible with the search for age. The questionnaire was developed by the researchers based on the attributes and the regulatory guidelines of the Primary Health Care, so that policy is in the validation process.

The data were put in a table and submitted to analysis using the Stata 9.0 software. To analyze the data were used descriptive measures (mean, median and standard deviation), bivariate analysis by crosstabs between variables and calculation of statistical significance between associations, using the chi-squared test, and as a convention of significance level a probability lower than 0.05 .

\section{Results}

The sample consisted of 180 adults, being $76.7 \%(n=138)$ women and $23.3 \%(n=42)$ men with an average of 36.65 years, median of 34.00 and standard deviation of 11, 55. This study obtained a Cronbach's alpha of 0.81 which reveals the existence of internal validity and reliable data on the construct. The ANOVA Cochran test was also calculated, being significant with $\mathrm{p}=0.00$.

The results showed that with respect to the quality of service received in Primary Health Care (Table 1), 46.1\% $(n=83)$ answered it was fair, $25.6 \%(n=46)$ rated the service received as good and $16.7 \%(n=30)$ rated it as poor.

In Table 2, with respect to the significant correlation between the service quality and the time spent by the user from his house to the health service, proven by the result of $p=0.023$, the results show that $93.9 \%(n=169)$ said they spend between 0 and 15 minutes from their house to the health service. A fact shows the proximity between houses and the healthcare unit.

Table 3 refers to the correlation observed between the classification of users and the following variables: the reception by service professionals $(p=0.042)$, service responsible for the user's health $(p=0.015)$, professional that receives the user and understands the need $(\mathrm{p}=0.000)$, and finally, if the user receives attention to talk

Table 1. Classification of service in primary health care from the user’s perspective. Santa Cruz/RN, Brazil, 2013.

\begin{tabular}{lcccccc}
\hline & Poor & Bad & Regular & Good & Excellent & Total \\
\hline Classification of the service quality & $\begin{array}{c}16.7 \% \\
(\mathrm{n}=30)\end{array}$ & $\begin{array}{c}8.9 \% \\
(\mathrm{n}=16)\end{array}$ & $\begin{array}{c}46.1 \% \\
(\mathrm{n}=83)\end{array}$ & $\begin{array}{c}25.6 \% \\
(\mathrm{n}=46)\end{array}$ & $\begin{array}{c}2.8 \% \\
(\mathrm{n}=05)\end{array} \quad \begin{array}{c}100 \% \\
(\mathrm{n}=180)\end{array}$ \\
\hline
\end{tabular}

Table 2. Correlation between the service quality and the time spent to reach the service. Santa Cruz/RN, Brazil, 2013.

\begin{tabular}{cccccc}
\hline & $\begin{array}{c}\text { From } 0 \text { to } \\
15 \mathrm{~min}\end{array}$ & $\begin{array}{c}\text { From } 16 \\
\text { to } 30 \mathrm{~min}\end{array}$ & $\begin{array}{c}\text { From } 31 \\
\text { to } 45 \mathrm{~min}\end{array}$ & $\begin{array}{c}\text { More than } \\
60 \mathrm{~min}\end{array}$ & $\mathrm{p}<0.05$ \\
$\begin{array}{c}\text { Total } \\
\text { Time spent from the user's home } \\
\text { to the health unit }\end{array}$ & $\begin{array}{c}93.9 \% \\
(\mathrm{n}=169)\end{array}$ & $\begin{array}{c}4.4 \% \\
(\mathrm{n}=8)\end{array}$ & $\begin{array}{c}0.6 \% \\
(\mathrm{n}=1)\end{array}$ & $\begin{array}{c}1.1 \% \\
(\mathrm{n}=2)\end{array}$ & $\begin{array}{c}0.023 \\
(\mathrm{n}=100 \%\end{array}$ \\
\hline
\end{tabular}

Table 3. Correlation between the quality of service and service specificities. Santa Cruz/RN, Brazil, 2013.

\begin{tabular}{|c|c|c|c|c|c|c|}
\hline & Never & Rarely & Sometimes & Frequently & Always & $\mathrm{p}<0.05$ \\
\hline Reception by professionals & $\begin{array}{c}12.2 \% \\
(\mathrm{n}=22)\end{array}$ & $\begin{array}{c}6.1 \% \\
(\mathrm{n}=11)\end{array}$ & $\begin{array}{c}18.3 \% \\
(n=33)\end{array}$ & $\begin{array}{c}3.8 \% \\
(n=7)\end{array}$ & $\begin{array}{c}59.4 \% \\
(n=107)\end{array}$ & 0.042 \\
\hline Service responsible for the user's health & $\begin{array}{c}22.8 \% \\
(\mathrm{n}=41)\end{array}$ & $\begin{array}{c}13.3 \% \\
(n=24)\end{array}$ & $\begin{array}{c}23.3 \% \\
(\mathrm{n}=42)\end{array}$ & $\begin{array}{c}0.6 \% \\
(n=1)\end{array}$ & $\begin{array}{c}40.0 \% \\
(n=72)\end{array}$ & 0.015 \\
\hline Professional that receives the user understands & $\begin{array}{c}10.0 \% \\
(n=18)\end{array}$ & $\begin{array}{c}6.1 \% \\
(n=11)\end{array}$ & $\begin{array}{c}33.3 \% \\
(n=60)\end{array}$ & $\begin{array}{c}1.7 \% \\
(n=3)\end{array}$ & $\begin{array}{c}48.9 \% \\
(n=88)\end{array}$ & 0.000 \\
\hline User receives attention when talking about & $\begin{array}{c}23.3 \% \\
(n=42)\end{array}$ & $\begin{array}{c}11.1 \% \\
(n=20)\end{array}$ & $\begin{array}{c}24.4 \% \\
(n=44)\end{array}$ & $\begin{array}{c}3.3 \% \\
(n=6)\end{array}$ & $\begin{array}{c}37.8 \% \\
(n=68)\end{array}$ & 0.000 \\
\hline
\end{tabular}


about personal problems $(\mathrm{p}=0.000)$.

In what refers to the reception of health professionals received by users, $59.4 \%(n=107)$ reported always being well received. Regarding the perception of the user about the responsibility of the health service to one's health, $40 \%(\mathrm{n}=72)$ said that the service will always be responsible for his/her health. Concerning the understanding of health professionals to the user's needs, $48.9 \%(n=88)$ said they are always well understood by professionals in the health service. In evaluating the responses related to the variable of attention given to the user's problems, $37.8 \%(n=68)$ reported always receiving attention when talking about their problems to healthcare professionals.

\section{Discussions}

The results of this study reveal that, concerning the gender, primary care service is most sought by women, which shows that women are more sensitive to the demand for health services, with the average age in the young adult age group. The study reveals a greater participation of women in health services, which is justified by the fact that women have a greater concern about their health compared to men, which contributes to the health services are more occupied by women seeking measures preventive of illness.

As to the service quality, users rated the service with a good range of regular. Showing that there are still actions that need to improve health care in the PHC network, and that these are in line with that recommended by the Ministry of Health and the constitution, when discussing implementation of comprehensiveness, fairness and universality.

Returning to the data of Table 1, the classification of service quality, the study of Coelho, Jorge and Araújo [5] states that in order to have a better performance of health professionals and better user satisfaction it is necessary to have a restructuring of health services, and that the health professional understands the social context in which the population is inserted. It's important that health professionals and the population are engaged in recognizing the need and adaptation of the real health needs.

Thus, one notes that the reception by the healthcare group seeks to decrease the vertical relationship between professionals and users that traditionally exists during consultations and thus to recognize its function and potentize the importance of continued and supportive care of the primary health care team.

It is essential that the primary health care meets the social needs and the population's needs where unity is inserted, aiming to meet the needs related to the health-illness process of individuals who seek this understanding in that place [6].

Hence, it is up to the health professional to seek strategies that will improve the quality of health care services offered to users, in order to clarify the guidelines of health status and consequently acquire a better life quality.

Table 3 shows the variable referring to the reception given by service professionals and, according to the results, when the population feels welcome at the clinic and enjoys a decent service, one realized that there is a greater adherence by users to the treatment and resolution of health problems, which then shows the formation of a relationship of trust and respect between users and health professionals [5].

The reception goes far beyond being well received at the Health Unit, since the way the health professional talks with the user is considered, the resolution that is given to the population's health problem, among other aspects. Therefore the reception is characterized as an event that tends to bring changes and that are able to redefine the context of the process of work in health, the same way they favor the emergence of changes mainly regarding the humanization policies [6].

In this study, it was noted that most users feel welcomed by health professionals because they give them the attention need. Besides, most users pointed to primary health care as responsible for their health. This reflects an improvement in the Brazilian health model, considering that it ensures an approach and builds links.

The study showed the existence of the need shown by users of health care towards professionals, which should have a look geared not only for what happens in the health unit, but also for other aspects, such as scheduling appointments that consider the user's work hours, among others. One could also notice the need for professionals to pay more attention and listen to the needs of each user, and that there is greater flexibility regarding attendance at the clinic [7].

Regarding the satisfaction of users of health units, the study indicates that there still are difficulties regarding coverage to the population's health, since there are many factors that make users feel dissatisfied with the quality of service provided by health professionals, i.e., factors that go beyond the services provided at the health unit, 
since one also considers the scope of reference and contra reference [7].

As a result, the better the care and attention given to the problems are raised by users during the care given by health professionals in the APS, the higher the resolution of health problems and, thus, greater user satisfaction, which leads to an improvement in health and promotes quality of life for the population.

The Primary Health Care is characterized by a level of service considered as a gateway to other levels of health care. However for this service to be effective, the quality of care offered by health professionals should be taken as paramount, so that it causes the patient to seek the service and aim to the continuity of the care.

This study shows relevant because the model implemented in Brazil of Primary Health Care has increasingly revealed his approach to the community, to ensure a comprehensive, universal and equitable assistance. This allows a continuous follow-up of the individual and allows early identification of the most common diseases by age group and sex, so that a set of interventions are planned and implemented free family and community, as recommended by the Unified Health System (SUS).

\section{Conclusions}

The Primary Health Care is characterized by a level of service considered as a gateway to other levels of health care. However for this service to be effective, the quality of care offered by health professionals should be taken as paramount, so that it causes the patient to seek the service and aim to the continuity of the care.

Therefore, in this study, it is concluded that the classification of the quality of service was mostly identified as regular and there is a need to develop strategies to deal with the weaknesses identified by users through answers such as "never" and "sometimes".

The strengthening of the PHC network is also proposed, since being a service oriented to the individual as a whole, the family and the community, when done effectively, brings great benefits and is presented positively for levels of secondary and tertiary care, the same way as to cater to the needs of the user and the articulation of the entire health system.

This study allowed us to make some considerations about the assistance that is being offered in Primary Health Care. The study has limitations because of data collection occurred with less than ideal sample.

It is hoped that this study from the user's perspective will sensitize professionals working in the primary health care network for quality of care and services targeted to the adult population, in order to preserve the humanization, the reception and an attention given to health focused on the real needs of this group. The importance of having professionals which know the environment in which the user is inserted is noteworthy since it contributes to the realization of health promotion. The right to health and respect for users has secured a higher quality in health services.

This care principle meets the operational guidelines of care in health from the National Primary Care Policy and the National Humanization Policy, both proposed by the Ministry of Health, with a view to a full, equitable and good service to the health of Brazilians inserted in each territory and that are waiting for a service with respect, dignity and support.

\section{References}

[1] Pereira, A.D., de Freitas, H.M.B., de Lima Ferreira, C.L., Marchiori, M.R.C.T., Souza, M.H.T. and Backes, D.S. (2010) Atentando para as singularidades humanas na atenção à saúde por meio do Diálogo e acolhimento. Revista Gaúcha de Enfermagem, 31, 55-61.

[2] Rocha, L.R.M., Veiga, D.F., e Oliveira, P.R., Song, E.H. and Ferreira, L.M. (2013) Health Service Quality Scale: Brazilian Portuguese Translation, Reliability and Validity. BMC Health Services Research, 13, 24. http://dx.doi.org/10.1186/1472-6963-13-24

[3] Ostermann, A.C. and Souza, J. (2009) Contribuições da análise da conversa para os estudos sobre o cuidado em saúde: Reflexões a partir das atribuições feitas por pacientes. Cadernos de Saúde Pública, 25, 1521-1533.

[4] Oenning, D., Oliveira, B.V. and Blatt, C.R. (2011) Conhecimento dos pacientes sobre os medicamentos prescritos após consulta médica e dispensação. Ciência \& Saúde Coletiva, 16, 3277-3283. http://dx.doi.org/10.1590/S1413-81232011000800027

[5] Travassos, C., Viacava, F., Pinheiro, R. and Brito, A. (2002) Utilização dos serviços de saúde no Brasil: gênero, características familiares e condição social. Revista Panamericana de Salud Pública/Pan American Journal of Public Health, 11, 365-373.

[6] Coelho, M.O., Jorge, M.S.B. and Araújo, M.E. (2009) O acesso por meio do acolhimento na atenção básica à saúde. 
Revista Baiana, 33, 440-452.

[7] Franco, F.A., Hino, P., Nichiata, L.Y.I. and Bertolozzi, M.R. (2012) A compreensão das necessidades de saúde segundo usuários de um serviço de saúde: Subsídios para a enfermagem. Escola Anna Nery, 16, 157-162. 